\title{
O GESTO MUSICAL NA SEQUENZA V PARA TROMBONE SOLO DE LUCIANO BERIO
}

William Henrique Claro de Souza, Rael Bertarelli Gimenes Toffolo

Universidade Estadual de Maringá - UEM, Centro de Ciências Humanas, Letras e Artes, Maringá, PR. E-mail: williamhenrique18@hotmail.com

\section{RESUMO}

O presente artigo tem o intuito identificar como o conceito de Gesto Musical é utilizado na obra Sequenza $V$ para trombone do compositor italiano Luciano Berio (1926-2003). Esta obra destacase no repertório tradicional do século $X X$ devido à sua associação com aspectos teatrais relacionados à figura do "clown" que são traduzidos em comportamentos musicais, incluindo a manipulação dos parâmetros sonoros tais como ritmo, melódico, dinâmico e morfológico. Para realizar tal análise, utilizamos os escritos do próprio compositor como ferramenta analítica, especialmente BERIO (1981 e 2006). No processo composicional no ciclo das Sequenza's para instrumento solo, Berio demonstra sua preocupação em retomar um discurso musical que dialogue com a história da música e com as propriedades técnicas do instrumento.

Palavras-chave: Gesto, Sequenza V, Luciano Berio, Música do Século XX, Composição.

\section{THE MUSICAL GESTURE IN LUCIANO BERIO'S SEQUENZA V FOR TROMBONE SOLO}

\begin{abstract}
The present article aims to identify how musical gesture appears in Luciano Berio's Sequenza $V$ for trombone solo. This particular piece stands out from the traditional repertoire of XX century music due of its association with theatrical aspects related to "clown" figure that are translated to musical behaviors, including manipulation of sound parameters such as rhythm, melody, dynamics and morphological development. For the analytical porpouses we used the composer's theoretical writings as analytical tools, mainly BERIO (1981 e 2006). The compositional process of the Sequenza's for solo instruments shows the importance of developing a musical discourse that dialogues with the historical and technical aspects of the musical instrument.
\end{abstract}

Keywords: Gesture, Sequenza V, Luciano Berio, XX Century Music, Composition. 


\section{INTRODUÇÃO}

Para o compositor Luciano Berio, "o pensamento deve tornar-se um recipiente consciente para o instrumento e seu legado físico" (Berio, 2006, p. 27, tradução nossa), ou seja, Berio considera o instrumento musical como um objeto histórico, em que, ao longo dos desenvolvimentos estéticos musicais, a prática musical marcou-o com as características da linguagem de seu tempo. A noção de gesto musical em Berio configura-se como forma de representação e significação musical, como elemento de agenciamento da estrutura da forma musical, e no âmbito da teatralidade, produzido pela relação do corpo físico do instrumentista e o resultado sonoro dessa ação corpórea.

O objetivo deste estudo foi, através da análise da Sequenza $V(1965)$, identificar de que forma as propriedades cênicas e gestuais interferem na escritura musical, e no desenvolvimento da obra.

\section{METODOLOGIA}

Para análise da Sequenza $V$ nos apoiaremos nos processos composicionais de Luciano Berio que utiliza estratégias de manipulação dos parâmetros musicais como, altura, intensidade, timbre e morfologia, superando os paradigmas básicos da música serial tal qual descritos em suas obras teóricas: Remembering the Future (2006) e Entrevista sobre a Música (Dalmonte, 1981), bem como relatadas em Knopke (1997) e Osmond-Smith (1991). Nas entrevistas realizadas por Dalmonte (1981), o compositor esboça a utilização e o desenvolvimento dos parâmetros sonoros tais como a dimensão temporal, a dinâmica, as alturas e a morfologia entendendo este último como a resultante timbrística que emerge do engendramento dos outros parâmetros. Tais formas de uso dos parâmetros musicais são realizadas de modo a produzir diferentes graus de tensão sonora, sendo esta dividida pelo compositor em três patamares: do mínimo, médio até o nível máximo de tensão. Por exemplo, a dimensão temporal encontra-se em grau máximo de tensão em momentos de rápidas articulações e nos momentos de duração máxima do som, enquanto o grau mínimo é constituído pelo silêncio e a tendência ao silêncio. (Dalmonte, 1981, p. 85). Já a dimensão das alturas encontrar-se-ia no grau máximo de tensão quando as notas se deslocam sobre zonas de registros contrastantes, ou intervalos de maior tensão harmônica, enquanto os graus médios e mínimos são obtidos a partir da diferenciação desse patamar. Quanto à dinâmica, os graus de máxima, média e mínima tensão ocorrem de acordo com a energia sonora ou os contrastes dinâmicos da textura sonora. O parâmetro morfológico para Berio é resultado do modo como considera a sonoridade de um dado instrumento; trata-se de "definir o grau de 
transformação acústica em relação a um modelo herdado, (...) com todas suas conotações histórico-acústicas" (Dalmonte, 1981, p. 85).

\section{RESULTADOS}

O fator fundamental que levou Luciano Berio a compor a Sequenza $V$ foi sua experiência de infância em assistir a uma apresentação do palhaço de circo Karl Adrien Wettach (1880-1959) conhecido como Grock. Segundo o próprio compositor, quando ele tinha apenas 11 anos, ao assistir um espetáculo de circo, no meio da atuação, o palhaço parou, olhou para o público e perguntou “warum?" (Por quê?) (Silva, 2010, p. 68). Este gesto intrigou o compositor, comentando mais tarde que "não sabia se havia de chorar ou rir e, no entanto, tinha vontade de fazer os dois". A peça é uma declarada homenagem de Luciano Berio à performance de Grock que carregava grande força simbólica e apresentava um forte caráter de ambiguidade e ironia.

Considerando a Sequenza $V$, no início pudemos perceber através das indicações na nota de performance a construção que é feita pelo instrumentista de uma personagem, caracterizada tanto por suas roupas (solicita-se o uso de um fraque) quanto pela maneira que se deve entrar em cena, fazendo alusão à um "showman", causando uma primeira impressão de estranhamento no público usual de concerto. Ao executar as primeiras notas o instrumentista inicialmente posicionado em pé, deve erguer e abaixar o instrumento repetidas vezes, gerando um comportamento fortemente previsível dos eventos que estão acontecendo. Entretanto, de forma inesperada o trombonista ergue o instrumento como se fosse repetir a ação, mas não executa nenhuma nota, quebrando toda a expectativa formada pelo ouvinte/espectador conforme ilustrado na Figura 1:

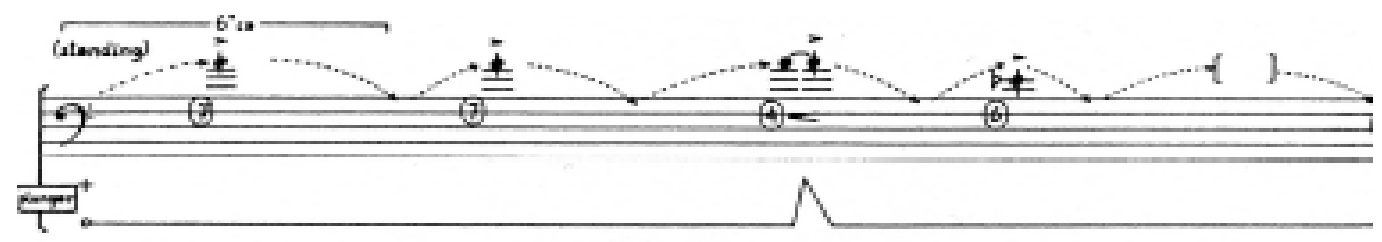

Figura 1. Excerto da partitura. Primeiro sistema.

A ação cênica sugerida com a entrada do instrumentista no palco e o movimento de erguer e abaixar o instrumento constrói o aspecto gestual e atingi visualmente o ouvinte/espectador, desencadeando conotações extra-musicais, além de gerar uma espécie de frustração, que por sua vez faz emergir uma ironia musical ao jogar com o forte contraste entre previsibilidade e frustação. Pelo fato do gesto ser construído sobre uma única nota, o Lá4, e em ritmo lento, 
percebe-se a necessidade em se manter o parâmetro temporal e harmônico estático para privilegiar a construção cênica do momento. O compositor explora as combinações feitas entre a voz do instrumentista e do trombone, fragmentando-a e unindo-a ao som do instrumento. Para tal, Berio utiliza-se da palavra "why?", o equivalente em inglês do "warum?" (Por quê?) pronunciado por Grock na performance que Berio assistiu quando criança. É solicitado ao instrumentista vocalizar as vogais [u-a-i] dentro do instrumento e por vezes imitá-las apenas com os sons do trombone. Esta fusão criada pelo compositor entre instrumento e voz ocorre segundo (Silva, 2010) em quatro fases diferentes e complementares, são elas:

1) A produção de sons vocais que são semelhantes aos feitos com trombone

2) A vocalização em simultâneo com a produção de sons pelo trombone

3) Vocalização enquanto inala

4) Pronunciação da palavra "Why?"

A voz também é utilizada como elemento harmônico, afim de, produzir os multifônicos no trombone, principalmente na segunda seção da peça, ilustrando a tentativa do compositor em desenvolver um discurso polifônico. No trecho representado na Figura 2 encontra-se o ponto nevrálgico da peça: o instrumentista rompe com o discurso puramente instrumental e passa a utilização pura da voz.

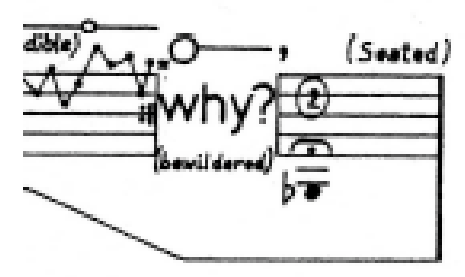

Figura 2. Excerto da partitura. Terceiro sistema

Em seguida, na segunda seção da obra o músico cessa o seu discurso de caráter mais cênico e deixa de posicionar-se de pé, sentando em uma cadeira no palco e iniciando uma interpretação mais introspectiva. Esta nova etapa de desenvolvimento do material musical retoma a ambição do compositor em transgredir o caráter monódico do trombone, aliando o uso da voz para alcançar tal objetivo. O primeiro parâmetro a se transformar é o da notação rítmica. No início do sistema há a indicação para que os eventos da área sugerida sejam executados em cerca de "12 
segundos", refletindo uma dilatação dos eventos, auxiliados pela figuração rítmica mais lenta de toda a seção.

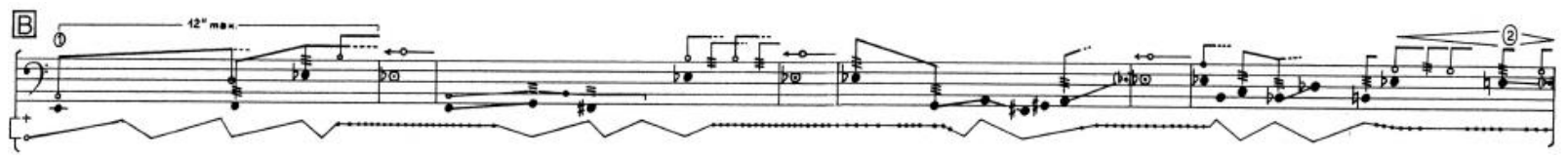

Figura 4.Excerto da partitura. Quarto sistema

O elemento cênico permanece nesta sessão, porém com outro caráter; o compositor sugere nas notas de performance que nesta sessão o instrumentista deva tocar "como se estivesse ensaiando em uma sala vazia"; como gesto cênico e também estrutural da obra, é indicado ao instrumentista que vocalize a nota sugerida dentro do instrumento enquanto inala.

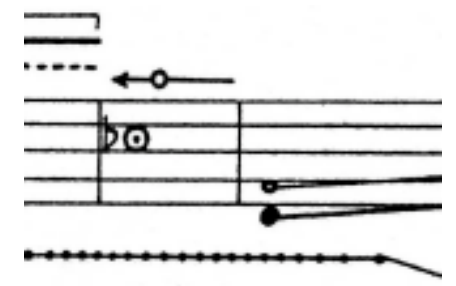

Figura 5. Excerto da partitura. Quarto sistema

As combinações entre voz e instrumento através de glissandos simultâneos, são constantes nesta segunda seção da peça; é transferido para a voz o uso do efeito rugoso causado pela técnica fluttertongue; como uma espécie de alquimia, estas variações e combinações tímbricas são usadas a fim de gerar um amalgama entre as distintas fontes sonoras. Nesta seção é adicionado um recurso instrumental que consiste em tocar a mesma nota através de várias posições da vara do instrumento, como ilustrados nas Figuras 7 e 8.

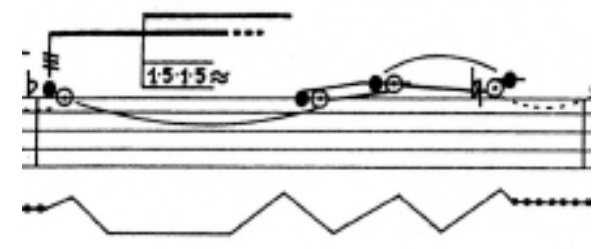

Figura 7. Excerto da partitura.

Sexto sistema

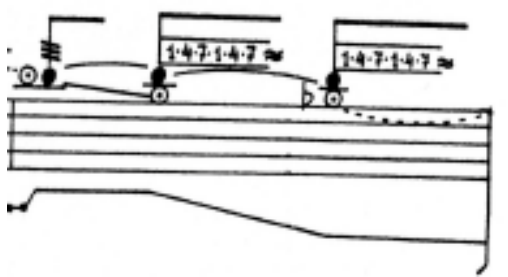

Figura 8. Excerto da partitura.

Sexto sistema

Este efeito, embora não cause uma nítida mudança tímbrica, realça o aspecto visual e consequentemente cênico do gesto. Gradualmente, o surgimento de notas executadas pelo trombone em registro contrastante e dinâmicas fortes sugerem uma crescente atividade rítmica e 
dinâmica, além de combinados com os vários movimentos do instrumento. As mudanças de posições da vara, a percussão da surdina na campana, a vocalização feita dentro do instrumento, e glissandos feitos entre voz e trombone, contribuem para percebermos um tratamento polifônico tanto do gesto físico quanto instrumental. De forma ambiciosa, o uso da simultaneidade entre voz e instrumento ocorre através de movimentos paralelos e oblíquos nesta nova etapa (Figura 9). Em toda a peça, encontramos a combinação e a realização por completa da simultaneidade das linhas melódicas de forma independente, ainda que brevemente, aqui como na Sequenza I para flauta, quando foi pioneiramente usado um multifônico, o compositor declara sua ambição em transformar e transgredir o idiomatismo do instrumento, apropriando-o e dando uma nova relação com a estética musical de seu século.

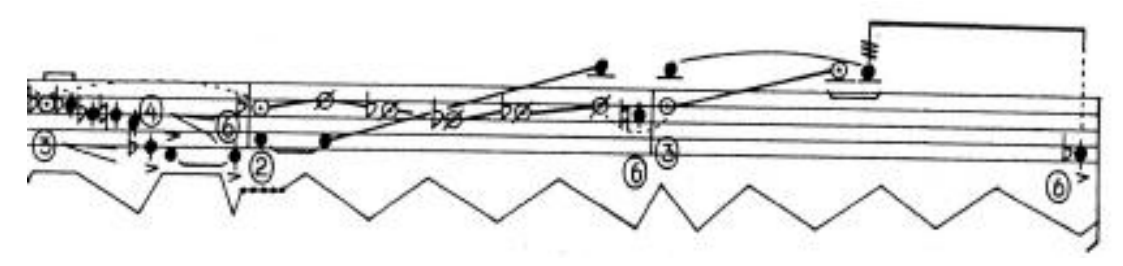

Figura 9. Excerto da partitura. Oitavo sistema

O nono sistema (Figura 10) mantém a atividade contrapontística entre voz e instrumento, porém agora com a voz mantendo o Sib3 enquanto o trombone de forma intermitente defere notas expandindo o registro usado pela voz, a surdina por sua vez, realiza concomitantemente com as notas do trombone uma espécie de filtro, acentuando o som da voz e destacando o timbre do trombone. Nesta etapa o discurso centra-se no trombone em que conduz ao fim do sistema o nível de tensão máxima, executando notas em seu registro extremo, alcançando o Fá5. Nota-se a intenção por parte do compositor em transformar o trimbre do instrumento a ponto de deixá-lo sem nitidez devido ao registro extremo, mas provavelmente em transformar esse elemento em algo de caráter cênico, já que de forma física para o instrumentista essa região se torna bastante desconfortável e difícil de ser executada, e é essa tensão física que o compositor provavelmente quis destacar, como uma outra faceta do palhaço.

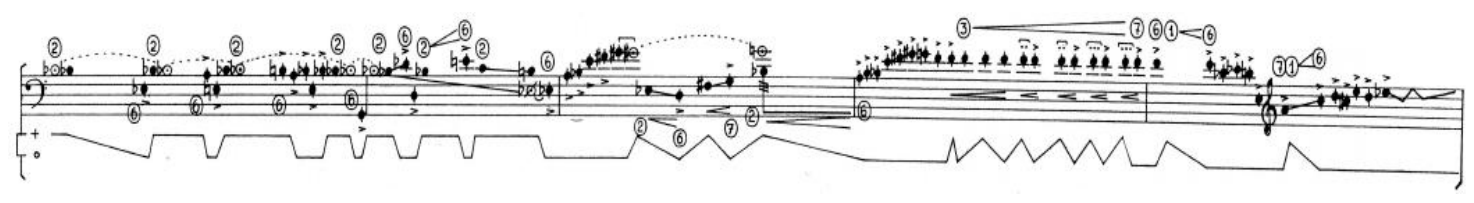

Figura 10. Excerto da partitura. Nono sistema 
No ultimo sistema da obra, Figura 11, é retomada as conotações antes associadas ao "personagem" do instrumentista, porém, o fator sonoro predomina sobre o cênico, o ato de abaixar o trombone enquanto o som é sustentado, causa um breve estranhamento, em que "engana" o ouvinte/espectador, em achar que o som emitido provinha unicamente do trombone, demonstrando mais uma vez a ironia e o senso de ilusão que o compositor brinca e manipula ao longo da peça.

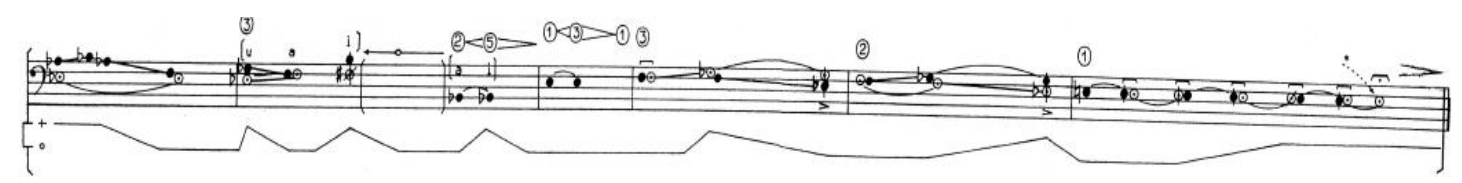

Figura 11. Excerto da partitura. Ultimo sistema.

\section{DISCUSSÃO}

As diversas formas de notação utilizadas no ciclo das Sequenze representam a inquietação e necessidade do compositor em dar suporte às diversas facetas da manipulação do sonoro e do gestual, em que presas à notação tradicional, tais propriedades não emergiriam nem seriam realizáveis de forma satisfatória. Desta forma, e aliado às possibilidades técnicas de sua época, Berio materializa em suas obras esta expansão do pensamento composicional juntamente com a performance musical. Todas as obras do ciclo das Sequenza's retratam a preocupação e vontade do compositor em retomar um direcionamento da linguagem musical de sua época que caminhasse em consonância com a referencialidade histórica, usando-a como elemento estrutural que preservasse e criasse novos desdobramentos no campo perceptual do ouvinte. A crítica ao qual Berio formou sobre os compositores de seu tempo justificava-se sobre o distanciamento que os compositores da segunda metade do século tomaram, como resultado da postura de eliminar na música a relação histórica com a linguagem musical, desvencilhando-se dos signos e significados intrínsecos a história musical até então, assim como a carga histórica contida nos próprios instrumentos musicais.

\section{CONCLUSÃO}

Pudemos através da análise da Sequenza $V$, identificar como o compositor faz emergir do cênico e do gesto físico do instrumentista propriedades que se articulam e se integram à escritura musical. As seções construídas ao longo da obra exploram diversas conotações no ouvinte/expectador que são desencadeadas pelos gestos vocais e físicos. A vocalização da palavra "Why?", as combinações simultâneas entre voz e instrumento, e a construção de atmosferas que se assemelham a um "número" de clown, onde o compositor reescreve na obra experiência vivida 
por ele próprio quando criança. A construção de tais comportamentos, só foram possíveis devido à manipulação por parte do compositor em gerenciar os parâmetros rítmicos, ora articulados para gerar tensão, o parâmetro melódico e dinâmico que também foram articulados a fim de criar comportamentos característicos, e o fator morfológico, que segundo o próprio compositor tem como intuito transformar o modelo herdado pelo instrumento, realizando na Sequenza $V$ o amalgama das conotações do Clown Grock.

\section{REFERÊNCIAS}

BERIO, L. Remembering the future. Harvard University Press.2006.

DALMONTE, R. Entrevista sobre a música. Rio de Janeiro: Civilização brasileira. 1981.

KNOPKE, I. Form and Virtuosity in Luciano Berio's Sequenza I. (Dissertação de Mestrado) Departamentof Music, Alberta, 1997.

OSMOND-SMITH, D. Berio. New York: Oxford University Press, 1991.

SILVA, D. A importância da Sequenza V no desenvolvimento do trombone. $2010.102 \mathrm{f}$. Dissertação (Mestrado). Escola Superior de Música e das Artes do espetáculo. 